\title{
Mulher climatérica: uma proposta de cuidado clínico de enfermagem baseada em ideias freireanas
}

\author{
Climacteric women: a proposal for nursing clinical care based on Freirean ideas
}

Mujer climatérica: una propuesta de cuidado clínico de enfermería basada en ideas freireanas

\author{
Cláudia Rejane Pinheiro Maciel Vidal', Karla Corrêa Lima Miranda", \\ Patrícia Neyva da Costa Pinheiro'I", Dafne Paiva Rodrigues ${ }^{\mathrm{IV}}$ \\ ' Universidade Federal do Ceará, Maternidade Escola Assis Chateaubriand. Universidade Estadual do Ceará, \\ Programa de Pós-Graduação em Cuidados Clínicos em Saúde (Mestranda).Fortaleza-CE, Brasil. \\ "Universidade Estadual do Ceará, Programa de Pós-Graduação em Cuidados Clínicos em Saúde, \\ Grupo de Pesquisa Políticas Práticas e Saberes em Saúde Coletiva. Fortaleza-CE, Brasil. \\ II' Universidade Federal do Ceará, Curso de Graduação em Enfermagem, \\ Programa de Pós-Graduação em Enfermagem. Fortaleza-CE, Brasil. \\ Iv Universidade Estadual do Ceará, Curso de Graduação em Enfermagem, Programa de Pós-Graduação em Cuidados \\ Clínicos em Saúde, Grupo de Pesquisa "Saúde da Mulher e Família" (Coordenadora). Fortaleza-CE, Brasil.
}

\section{Submissão: 22-09-2010 Aprovação: 02-10-2012}

\section{RESUMO}

O estudo objetiva dialogar entre os conceitos cuidar e educar e propor uma estratégia de educação em saúde como possibilidade de cuidado clínico de Enfermagem para mulheres no climatério baseada nos princípios educativos de Paulo Freire. Ao longo dos anos, diferentes paradigmas de Educação em Saúde são condicionados por diferentes estratégias, muitas delas reducionistas, o que requer questionamentos e implementação de ações mais integrantes e participativas. A partir deste pensamento, buscamos uma possibilidade de educação que contemple o Outro em sua complexidade, possibilitando que a mulher em sua fase climatérica possa também ser assistida de forma integral. Neste cenário, visualizamos os princípios de Paulo Freire como marco norteador para este desenvolvimento, por ele mostrar uma educação dialogada, solidária, sem arrogância, articulando o saber científico com o conhecimento popular, traduzindo seu método em um trabalho coletivo.

Descritores: Enfermagem; Educação em Saúde; Climatério; Saúde da Mulher.

\section{ABSTRACT}

The study aims to discuss the concepts of caring and education and propose a strategy for health education as a possibility for clinical nursing care for women in menopause based on the educational principles of Paulo Freire. Over the years, different paradigms of Health Education are conditioned by different strategies, many of them reductionists, which require questioning and implementation of more integral and participatory actions. From this thought, we seek an opportunity for education that includes the "Other" in their complexity, enabling the women in their climacteric phase can also be assisted in full. In this scenario, we visualize the principles of Paulo Freire as a framework to guide this development; it shows a dialectic education, solidarity, without arrogance, articulating the scientific knowledge and popular knowledge, translating his method in a collective work.

Key words: Nursing; Health Education; Climacteric; Women's Health.

\section{RESUMEN}

El estudio objetiva dialogar entre los conceptos cuidar y educar y proponer una estrategia de educación en salud como posibilidad de cuidado clínico de Enfermería para mujeres en el climaterio basada en los principios educativos de Paulo Freire. En el transcurso de los años, diferentes paradigmas de Educación en Salud están condicionados por diferentes estrategias, muchas de ellas reduccionistas, lo que requiere cuestionamientos e implementación de acciones más integrantes y participativas. A partir de este pensamiento, buscamos una posibilidad de educación que contemple al Otro en su complejidad, posibilitando que la mujer en su fase climatérica también pueda ser asistida de forma integral. En este escenario, visualizamos los principios de Paulo Freire como marco orientador para este desarrollo, por mostrar una educación dialogada, solidaria, sin arrogancia, articulando el conocimiento científico con el conocimiento popular, traduciendo su método en un trabajo colectivo.

Palabras clave: Enfermería; Educación en Salud; Climaterio; Salud de la Mujer. 


\section{INTRODUÇÃO}

Nos últimos anos, o climatério passou a ser um tema bastante discutido, haja vista o aumento da expectativa de vida da população e com ela a preocupação com a qualidade de vida. Atualmente, um dos maiores desejos das mulheres é viver a fase do climatério com melhor qualidade, sem preconceitos e opressão, desmitificando idéias preconcebidas imposta pela cultura brasileira que apresenta uma mulher climatérica sem perspectivas outras que vão além da fase reprodutiva. Quando na realidade a menopausa significa apenas o fim do período de fecundidade.

Climatério, segundo o Ministério da Saúde é a fase de transição entre a fase reprodutiva e a não reprodutiva da vida da mulher, estendendo-se até os 65anos de idade. Menopausa caracteriza-se pela ausência de ciclo menstrual depois de passado 12 meses da sua ocorrência ${ }^{(1)}$.

Este período não representa uma doença e sim uma fase da vida da mulher, em que a maioria delas passa por este momento sem queixas ou necessidade de medicamentos. No entanto, outras apresentam alterações de variável intensidade e que geralmente não são freqüentes.

O Programa de Assistência Integral à Saúde da Mulher (PAISM), instituído pelo Ministério da Saúde foi operacionalizado em 1984, atendendo às reivindicações do movimento de mulheres, marcando, sobretudo, um rompimento conceitual com os princípios norteadores da política de saúde das muIheres e os critérios para eleição de prioridades nesta área(2).

Este programa incorporou como princípios e diretrizes as propostas de descentralização, hierarquização e regionalização dos serviços, bem como a integralidade e a eqüidade da atenção. Paralelamente, no âmbito do Movimento Sanitário, se concebia a estrutura conceitual que embasaria a formulação do Sistema Único de Saúde (SUS), onde neste incluía ações educativas, preventivas, de diagnóstico, tratamento e recuperação, englobando a assistência à mulher em clínica ginecológica, no pré-natal, parto e puerpério, no climatério, em planejamento familiar, DST, câncer de colo de útero e de mama, além de outras necessidades identificadas a partir do perfil populacional das mulheres ${ }^{(3)}$.

Embora já tenham se passado 25 anos da formulação e implantação do PAISM e os serviços de saúde tenha conhecimento de tudo isto, ainda assim, observamos um impasse no acompanhamento à saúde da mulher climatérica, notando-se uma deficiência na assistência, que não corresponde ao que se propôs o referido Programa, quando este inclui em seus preceitos ações educativas e preventivas de saúde, de forma que os cidadãos tenham conhecimento do seu estado de saúde ou doença.

Atualmente o cuidado dispensado às mulheres climatéricas se configura em estratégias de cuidado voltado mais para a doença, para a "medicalização" do corpo, de forma que o sujeito não é percebido como parte fundamental na construção da prática dos serviços de saúde, condição contrária quando se ressalta que o cuidado deve se manifestar na preservação do potencial saudável dos cidadãos e estar sujeito a uma visão ética que contemple a vida como um bem valioso em $\mathrm{si}^{(4)}$.
Na concepção da Enfermagem, cuidar consiste em desafiar esforços trans-pessoais de um ser humano para outro, em busca de promover e preservar a humanidade, ajudando pessoas a encontrar significados na doença, sofrimento e dor, bem como na existência. Sendo ainda uma forma de ajudar outra pessoa a obter autoconhecimento, controle e autocura, quando na verdade um sentimento de harmonia interna é sentido e restaurado, independente das circunstâncias externas ${ }^{(5)}$.

Neste sentido, os profissionais de saúde, dentre os quais, os enfermeiros, poderão se utilizar de estratégias de educação em saúde e apontar caminhos para o autocuidado, como uma alternativa de participação ativa, que promove a autonomia dos sujeitos, como percurso da sua realidade de vida.

É necessário desenvolver uma prática educativa consciente e crítica para o futuro, no contexto da qual entendamos o ser humano em sua complexidade. O conhecimento, porém, na maioria das vezes, é fragmentado por disciplinas, não sendo visível sua recomposição. Atualmente, podemos visualizar as marcas dessa fragmentação, inclusive no conhecimento científico e na educação ${ }^{(6)}$.

Neste cenário de busca de um modelo de educação que contemple o outro em sua complexidade, visualizamos os princípios de Paulo Freire como marco norteador para este desenvolvimento, por ele mostrar uma educação dialogada, solidária, sem arrogância, articulando o saber científico com o conhecimento do outro, traduzindo seu método em um trabalho coletivo.

Acreditamos que a proposta de Paulo Freire para a educação de adultos não possa ser transferida na íntegra para a Educação em Saúde, embora as deficiências de conhecimento de muitas pessoas apontem para a necessidade de alfabetizá-las em saúde. Ou seja, devem aprender, a partir do seu mundo, das suas condições de sobrevivência, os conteúdos representativos para a Promoção da Saúde e prevenção das doenças.

Estimuladas por estas questões, objetivamos neste artigo, dialogar entre os conceitos cuidar e educar e propor uma estratégia de educação em saúde como possibilidade de cuidado clínico de Enfermagem para mulheres no climatério baseada nos princípios educativos de Paulo Freire.

\section{IDEIAS FREIREANAS: a base para o cuidado de enferma-} gem a mulheres no climatério, numa visão holística

Cultura é toda criação humana, pois consiste em criar e não repetir. "Trata-se da aquisição sistemática da experiência humana", construção de sentidos que Ihe são atribuídos, as ações e comportamentos em suas relações consigo mesmo e com os outros, com a natureza e com as divindades, sua atuação sobre a natureza e a sociedade ${ }^{(7)}$.

Para tanto se reflete sobre uma educação em que o homem fosse capaz de superar suas atitudes ingênuas, diante de sua realidade ${ }^{(9)}$. Sendo desvelado que a resposta poderia estar em um método educativo ativo, dialogal, crítico e conscientizador, na modificação programática da educação e para isto, o principal caminho é o diálogo ${ }^{(7)}$.

Freire concebe a educação como uma relação dialógica entre educando e educador, onde a liberdade é um pressuposto fundamental, pois possibilita ao sujeito uma discussão 
de sua problemática e de sua inserção no mundo. Por isso ele fala não apenas de uma leitura da palavra, mas de uma leitura do mundo, pois essa educação parte do pressuposto que ninguém educa ninguém e que todos aprendem em comunhão, a partir da leitura coletiva do mundo. Desta forma, o autor propõe e defende uma educação a partir da realidade do sujeito, ou seja, uma educação crítica-dialógica, onde o educador facilita a construção de perguntas e não de respostas prontas e acabadas. Ou seja, é a articulação do saber crítico com o popular, mediatizados pela experiência do mundo ${ }^{(8-7)}$.

A Enfermagem em seu crescimento como profissão, tem assumido diversos papéis e posições, sendo seu objeto de estudo o cuidar/cuidado. Diante da subjetividade da questão prática vivenciada pelo profissional de Enfermagem, que por vezes se encontra à frente de inúmeras atividades rotineiras, pode se ver diante de um enigma, tendo dificuldades em compreender as múltiplas faces deste conceito.

De acordo com este pensamento, sobre o reconhecimento da objetividade/subjetividade das maneiras de cuidar em Enfermagem, realizou-se um estudo que resultou em 46 formas de cuidar, desde a admissão até a alta hospitalar/óbito, mostrando que, na diversidade de interações do indivíduo com o profissional, diversas formas objetivas podem ser identificadas ${ }^{(9)}$.

Assim, entre as tantas formas de cuidar, nos deteremos na maneira social de cuidar do outro, sendo esta definida como o cuidar regulado pela preocupação com o sofrimento do outro, principalmente aqueles em situação de exclusão, os mais pobres, aqueles sujeitos à condição de desigualdade social, que no Brasil tem representatividade bastante significativa, na qualidade de usuários dos serviços de saúde pública ${ }^{(9)}$.

A autora supracitada complementa que esta maneira de cuidar está fundamentada no compromisso social e na preocupação com o outro. As ações de educação e saúde são objetivadas a instruir os indivíduos a como tratar os fatores comportamentais, como cuidar de si mesmo e como lidar com os assuntos de saúde antes deles se tornarem problemas persistentes. Deste modo, pode-se afirmar que é o compromisso social manifestado em uma maneira de cuidar em Enfermagem.

Esta assunção concorda com a anterior quando acentua que o cuidado implica um modo de ser, mediante o qual a pessoa sai de si e se centra no outro com desvelo e solicitude, como uma forma de preocupação, inquietação e sentido de responsabilidade pelo outro ${ }^{(10)}$.

Com base nos fatos citados necessitamos repensar a respeito deste cuidado, especificamente, pois estudos demonstraram o descontentamento das climatéricas em razão da vaga assistência destinada a elas, da carência de informações. Elas salientam que os serviços de saúde estão voltados para atender as mulheres enquanto reprodutivas, ficando uma lacuna assistencial na atenção integral à saúde da mulher ${ }^{(11-12)}$.

Corroborando esta ideia, estudo mostra que as mulheres no climatério apresentam em sua maioria certo desconhecimento cognitivo do conceito do termo climatério, expressam este conceito de formas distintas. Algumas nada sabem de imediato, não referem um pensamento lógico; no entanto, ideias são trazidas pelas mulheres quando interligam o termo climatério a serviços de saúde, com funções médicas e tratamentos especializados, sugerindo desta forma que estas mulheres estão desprovidas de informação, quer dizer, estão vazias de conhecimento em relação ao que se passa com seu corpo, levando-nos a crer que existe carência do diálogo, fator primordial na comunicação entre profissionais e clientes ${ }^{(13)}$.

Portanto, faz-se necessário o desenvolvimento de práticas assistenciais que levem em consideração a individualidade, a capacidade para formular a sua história de vida, única, baseada em experiências próprias, na interação com os outros e com o ambiente, respeitando-se crenças, costumes, valores, conhecimentos e cultura.

Sendo assim, podemos refletir sobre a importância da democratização da cultura, onde o homem atua como fazedor de sua história e não como espectador dela, enfim, o homem precisa estar no mundo e com o mundo, assumindo papel de sujeito da sua história e não como mero objeto dela.

No entanto, é acentuado que conhecer e educar não é apenas acumular conhecimentos, informações, mas, antes de tudo, implica em mudança de atitude, não apenas assimilando conteúdos universais, mas saber pensar ${ }^{(14)}$. Para Piaget aprender é estabelecer relações. Paulo Freire complementa, dizendo que saber é criar vínculos ${ }^{(15)}$.

Com efeito, se aprender é estabelecer relações e saber é criar vínculos, denotamos que devam se estabelecer relações e criar vínculos com as climatéricas, que mulheres e profissionais de saúde nesta relação aprendam mutuamente como forma de promover saúde.

Desse modo, como um dos requisitos das ações básicas de saúde, a ação educativa deve ser desenvolvida por todos os profissionais de saúde e estar inserida em todas as atividades, devendo ocorrer em todo e qualquer contato entre profissional e cliente, com o intento de levar a mulher a refletir sobre sua saúde, adotando práticas para sua melhoria ou manutenção, realizando mudanças e novos hábitos para a solução de seus problemas ${ }^{(2)}$.

Sendo assim, o profissional deve ser um instrumento para que a mulher adquira autonomia no seu agir e aumente a capacidade de enfrentar situações adversas próprias desta fase e decida sobre sua vida e saúde.

\section{IDEIAS FREIREANAS: propostas de cuidado clínico de En- fermagem a mulheres no climatério}

Defendemos que é possível forjar uma clínica na enfermagem para emancipação do sujeito, valorizando as formas que o sujeito encontra de se apropriar de sua história de vida, seus signos e de seus sintomas; as maneiras com as quais ele significa a própria vida, contemplando os aspectos culturais em que se encontra esta mulher.

Considerando que Freire pensa a educação como um ato de conhecimento, uma aproximação critica da realidade, e que, com a apropriação deste conhecimento, a pessoa consiga conhecer a si e ao mundo, movendo-se ao encontro da autotransformação e da intervenção no mundo, logo, o ato de conhecimento é a descoberta, é estar surpreso diante de algo ignorado, não "entulhamento" de conteúdos; é a construção de algo. O conhecimento não se dá apenas em sua dimensão 
individual, porquanto ocorre na dimensão social, sendo o diálogo o mediador deste processo.

Entendemos, então que, no diálogo, podemos construir com a climatérica uma forma de conhecimento. Podemos iniciar pela informação, para ela se apropriar de noções e informações básicas, para posteriormente ampliarmos com esta mulher outras formas de conhecimento; aquele conhecimento que Freire postula: que o sujeito consiga formular a sua pergunta e ele mesmo busque sua resposta.

Logo, enfermeiro e cliente, no caso a mulher no climatério, cointencionados à realidade, se encontram numa tarefa em que ambos são sujeitos no ato, não só de desvendá-la criticamente e, assim, criticamente conhecê-la, mas também no de recriar este conhecimento.

Para Freire, o conhecimento é construído de forma integradora e interativa. Conhecer é descobrir e construir, e não copiar é necessário reinventar um conhecimento que tenha "feições de beleza".

O cuidado de Enfermagem, por conseguinte, pela alegria de viver e de aprender, quando o diálogo entre esses sujeitos - enfermeiro e cliente - é a mola do relacionamento, é um compromisso ético. É nesse encontro amoroso o espaço onde enfermeiro e cliente podem construir.

Assim, o pensamento de Freire é citado quando fala da necessidade da redescoberta do ser humano de forma integral. Logo, o conhecer, o sentir e o fazer são condições fundamentais para existência da aprendizagem. Pois quando ensinamos precisamos levar em consideração a cognição, o afetivo e o psicomotor, que são domínios fundamentais no processo da aprendizagem $^{(16)}$.

Para que isso aconteça, faz-se necessário o enfermeiro abdicar do seu lugar de detentor do saber, e por meio da criatividade, estimular uma ação e reflexão sobre a realidade, questionando-as numa perspectiva crítica sobre a realidade, bem como da sua possibilidade de ser transformada.

Desta forma, propomos que a mulher climatérica, com apoio nas ideias freireanas, possa:

1. entender o que se passa com ela na fase do climatério;

2. interpretar essa fase em sua vida;

3. fazer a sua pergunta;

4. criar a sua resposta; e

5. buscar possibilidades de superação.

Apostamos e defendemos um cuidado clínico de Enfermagem crítico-dialógico, no qual exista uma pergunta formulada pela mulher climatérica. É pela relação dialógica que enfermeiro-mulher podem refletir, criar e recriar um conhecimento coletivo articulando seus saberes mediatizados pelas experiências do mundo. É isso que nos ensina Freire.

\section{CONSIDERAÇÕES FINAIS}

Considerando que o climatério é um período de transformação, adaptação e até aceitação, permeado de tabus e preconceitos, podendo trazer consigo sentimentos diversos e sendo uma fase comum a todas as mulheres, é necessário que profissionais de saúde tenham uma melhor compreensão do ser mulher climatérica.

Reconhecendo que existe uma íntima relação entre contexto social e cultural, e a forma como a mulher vê o climatério, é necessário que ocorra a compreensão de que o climatério não deve ser caracterizado como doença e sim como saúde, requerendo uma maior aproximação entre profissionais, serviços e clientela a fim de que se conheça este universo de mulheres e, assim, se supra a carência de cuidados existentes.

Dessa forma, precisa-se pensar a educação em saúde de modo ampliado, que comporte ações que favoreçam as pessoas a alcançar capacidade de autonomia e de assumirem atitudes positivas. Para tanto, é preciso levar em consideração as experiências individuais, favorecendo sua participação e contribuindo para o alcance de respostas satisfatórias e, ao mesmo tempo, equilíbrio de sua saúde.

Neste sentido, propomos que o atual modelo assistencial volte seu "olhar" à mulher além de sua fase reprodutiva, permitindo a visibilidade que, até então, tem se mantido às margens do cuidado. Faz-se necessário reformular e implementar estratégias incluindo as mulheres em todo seu ciclo de vida, de forma que se sintam responsáveis pelo autocuidado, ao mesmo tempo em que os profissionais se coloquem disponíveis para o trabalho de educação e promoção da saúde.

Pensando na defesa de um projeto de cuidado clínico de Enfermagem para mulheres no climatério pautado na possibilidade de intervenção da realidade, refletindo criticamente, intervindo e agindo, escolhendo e decidindo, propomos um cuidado com arrimo nas idéias freireanas baseadas no diálogo para conscientização e autonomia do outro.

Assim, no campo assistencial de Enfermagem torna-se necessário realizar e experimentar-se como sujeitos, sendo o papel do enfermeiro estabelecer uma relação horizontal com as mulheres no climatério, de forma que elas se sintam valorizadas e motivadas a refletirem sobre seu modo de vida e seus limites.

No que se refere à assistência a saúde em geral, é essencial que reconheçamos que mudanças de hábitos que favoreçam uma vida saudável devem ser incentivadas, tais como: atividades físicas (dança, caminhada com o tempo recomendado, natação), dieta rica em cálcio e proteínas e hipogordurosas, abandono do etilismo e tabagismo; prevenção de doenças crônicas como a hipertensão e o diabetes mellitus. A utilização de medicamentos pode ser indicado quando garantido o acesso à ele, quando for uma opção da mulher em fazer uso destes para controle da sintomatologia ocasionada pela carência hormonal, quando esta se exacerba neste momento da vida feminina.

Assim sendo, esperamos que profissionais de saúde, que estão particularmente mais próximos da mulher no climatério, tenham consciência e visão totalizadora no continuum de Educação em Saúde, respeitando e valorizando a vida do ser humano, tendo em vista os preceitos éticos atribuídos à formação do indivíduo. Isto porque o climatério é uma fase na qual a mulher, diante de várias modificações por que passa, está no começo de uma nova etapa. Precisamos, para isto, que profissionais e mulheres no climatério caminhem juntos no sentido de criar, construir, reconstruir e transformar. 


\section{REFERÊNCIAS}

1. Ministério da Saúde. Guia de saúde da mulher. Brasília: MS; 2004. p. 113

2. Ministério da Saúde. Assistência Integral à Saúde da MuIher: Bases de Ação Programática. Brasília: Centro de Documentação; 1984.

3. Ministério da Saúde [homepage na internet] Saúde da Mulher. [acesso em 20 abr 2009]. Disponível em < http://portal.saude.gov.br/portal/saude/visualizar_texto. $\mathrm{cfm}$ idtxt $=25236>$

4. Souza ML, Sartor VVB, Padilha MICS, Prado, MLO. Cuidado em Enfermagem: Uma Aproximação Teórica. Texto \& Contexto Enferm 2005,14(2): 266-70.

5. Waldow VR, Lopes MJM, Meyer DE. Maneiras de cuidar, maneiras de ensinar. Porto Alegre: ARTES MÉDICAS; 1998.

6. Miranda, KCL; Barroso, MGT. Aconselhamento em HIV/ AIDS: Análise à luz de Paulo Freire. Rev. Latino-Am Enferm 2007,15(1):100-5.

7. Freire. P. Educação como prática da liberdade. 26. ed. Rio de Janeiro: Paz e Terra; 2002.

8. Freire. P. A educação na cidade. 3. Ed. São Paulo: Cortez; 1999.
9. Coelho MJ. Maneiras de cuidar em Enfermagem. Rev Bras Enferm 2006;59(6):745-51.

10. Boff L. O cuidado essencial: princípio de um novo ethos. Inclusão Soc 2005;1(1)28-35.

11. Daoud IG. Encontros e Desencontros das Mulheres Climatéricas que Buscam Assistência em Serviço do Sistema Único de Saúde. Rev Enferm 2002,10(1):33-37.

12. Freitas KM, Silva ARV, Silva R. M. Mulheres Vivenciando o Climatério. Acta Sci. Health Sci 2004;26(1):121-8.

13. Vidal CRPM. Mulheres no Climatério: desconhecimento, relacionamentos e estratégias. Ceará. Dissertação [Cuidados Clínicos em Saúde]- Universidade Estadual do Ceará; 2009.

14. Freire P. À sombra desta mangueira. 4. ed. Olho D'água; 2001.

15. Gadotti M. Um legado de esperança. São Paulo: Cortez; 2001.

16. Souza JF. Atualidade de Paulo Freire: contribuição ao debate sobre a educação na diversidade cultural. São Paulo: Cortez; 2002. 